\title{
Clinical presentation and surgical outcomes of intramedullary neurenteric cysts
}

\author{
Tao Yang, MD,' Liang Wu, MD, Jingyi Fang, MD, ${ }^{1}$ Chenlong Yang, MD, ${ }^{1}$ Xiaofeng Deng, MD,1 and \\ Yulun Xu, MD, PhD' \\ 1 Department of Neurosurgery, China National Clinical Research Center for Neurological Diseases, Beijing Tiantan Hospital; and \\ ${ }^{2}$ Department of Neuropathology, Beijing Neurosurgical Institute, Capital Medical University, Beijing, China
}

\begin{abstract}
OBJECT Intramedullary neurenteric cysts (NECs) are exceedingly rare lesions and have been previously reported in case reports. The aim of this study was to determine the clinical manifestations, radiological features, and long-term prognosis of patients with such lesions.
\end{abstract}

METHODS The authors retrospectively reviewed the records of 13 patients with an intramedullary NEC. Each patient underwent MRI, laminotomy, and microsurgery. The accurate diagnosis was based on imaging and pathology findings. Each patient's follow-up status was determined through individual office visits and a structured telephone interview.

RESULTS The series included 7 male and 6 female patients. Progressive or intermittent motor deficit was the main symptom associated with or without pain or sensory disturbance. Five cysts were located in the cervical cord, 1 in the cervicothoracic cord, 3 in the thoracic cord, and 4 in the conus medullaris. Concurrent malformations included scoliosis ( 3 cases), fusion of rib ( 1 case), enlarged spinal canal ( 1 case), tethered spinal cord (1 case), and ectocardia (1 case). Gross-total resection of the cyst was achieved in 8 cases, and subtotal resection (STR) was achieved in 5 cases. All patients were followed up, with a mean duration of 66.5 months. Cyst recurrence was observed in 4 cases after STR. In 2 cases the patients underwent reoperation; the other 2 patients remained clinically stable and did not undergo reoperation. At the last evaluation, neurological function was improved in 11 patients and remained stable in 2 patients.

CONCLUSIONS Intramedullary NECs should be considered in the differential diagnosis of a middle-aged patient with intermittent neurological symptoms and concurrent malformations. Early surgery is advocated to prevent permanent neurological deficits. When gross-total resection cannot be achieved, maximally safe removal under the protection of intraoperative neuromonitoring is advised. Because of the high risk of cyst recurrence, routine follow-up MRI is needed. If a residual cyst shows obvious regrowth and results in neurological deficits, timely reoperation with a goal of STR should be performed.

http://thejns.org/doi/abs/10.3171/2014.11.SPINE14352

KEY WORDS neurenteric cyst; intramedullary cyst; surgical resection; long-term outcome; congenital

$\mathrm{N}$ EURENTERIC cysts (NECs) are rare congenital malformations of the central nervous system and are lined by epithelium of an intestinal nature. Most intraspinal NECs are localized in the intradural extramedullary (IDEM) compartment of the cervicothoracic junction and are associated with bone, soft-tissue, and visceral abnormalities. ${ }^{10,17,26}$ However, NECs rarely occur in an intramedullary location, and intramedullary NECs represent $<5 \%$ of intraspinal NECs. ${ }^{22}$

To our knowledge, only 38 cases of NEC (with or without concurrent malformations) have been described since the publication of the earliest report in $1954 .^{2-4,8,10,12-14,16,18-}$ 22,24-27,29-35,37-42,44,45 Most previous publications regarding intramedullary NECs have been case reports. Therefore, the optimal management for this lesion has not been fully determined. In this article, we present and discuss the clinical manifestations, radiological features, and long-term outcomes of 13 patients with an intramedullary NEC, the first case series from a single center.

\section{Methods}

After obtaining approval from the institutional review board of Beijing Tiantan Hospital, Capital Medical University, we retrospectively reviewed the data of 13 patients with an intramedullary NEC seen in our depart-

ABBREVIATIONS CDVT = cystic dilation of the ventriculus terminalis; EMA = epithelial membrane antigen; GFAP = glial fibrillary acidic protein; GTR = gross-total resection; IDEM = intradural extramedullary; NEC = neurenteric cyst; STR = subtotal resection; T1WI = T1-weighted imaging; T2WI = T2-weighted imaging.

SUBMITTED April 3, 2014. ACCEPTED November 4, 2014

INCLUDE WHEN CITING Published online April 24, 2015; DOI: 10.3171/2014.11.SPINE14352.

DISCLOSURE The authors report no conflict of interest concerning the materials or methods used in this study or the findings specified in this paper. 
ment between 2003 and 2013. Preoperatively, each patient underwent plain radiography and MRI of the corresponding segments of the spine. CT was performed only in patients who had questionable bony abnormalities on MR images or a plain radiograph. Laminotomy was performed through a posterior approach with intraoperative monitoring of somatosensory and motor evoked potentials. Care was taken during subperiosteal dissection of the paraspinal muscles to preserve the facet capsules. A high-speed drill was used for cutting off the lamina bilaterally. The drill was angled laterally to achieve an oblique cut line with minimal loss of bony substance. After cutting off the lamina, the interspinous ligaments and ligamentum flavum were cut with scissors, and the lamina was dissected free from the epidural fat. Titanium miniplates were attached to the lamina and fixed with 3- to 5-mm screws. After intraspinal surgery, the lamina was reinserted, and the miniplates were secured with screws.

For inclusion into the study, a patient had to meet the following criteria: 1) initial treatment in the Beijing Tiantan Hospital, 2) a purely intramedullary cyst documented on MRI, 3) intraoperative confirmation of an intramedullary cyst, 4) definite pathological diagnosis of NEC, and 5) complete follow-up data available. The modified McCormick classification (Table 1) was applied to assess neurological function. ${ }^{1,23}$ Each patient's follow-up status was determined through individual office visits and a structured telephone interview. The questions about movement of limbs, pain, sensory disturbance, and bladder and bowl functions were asked during the telephone follow-up.

\section{Results}

\section{Clinical Presentation}

There were 7 male and 6 female patients aged from 10 to 64 years (mean 36.7 years). In the same time frame,

\section{TABLE 1. Modified McCormick classification*}

\begin{tabular}{|c|c|}
\hline Grade & Definition \\
\hline I & $\begin{array}{l}\text { Neurologically normal; gait normal; normal professional } \\
\text { activity }\end{array}$ \\
\hline $\mathrm{lb}$ & $\begin{array}{l}\text { Tired after walking several kilometers; running is impos- } \\
\text { sible, or moderate sensorimotor deficit does not signifi- } \\
\text { cantly affect the involved limb; moderate discomfort in } \\
\text { professional activity }\end{array}$ \\
\hline II & $\begin{array}{l}\text { Presence of sensorimotor deficit affecting function of } \\
\text { involved limb; mild-to-moderate gait difficulty; severe } \\
\text { pain or dysesthetic syndrome impairs quality of life; } \\
\text { independent function and ambulation maintained }\end{array}$ \\
\hline III & $\begin{array}{l}\text { More severe neurological deficit; requires cane and/or } \\
\text { brace for ambulation or maintains significant bilateral } \\
\text { upper-extremity impairment; may or may not function } \\
\text { independently }\end{array}$ \\
\hline IV & $\begin{array}{l}\text { Severe neurological deficit; requires wheelchair or cane } \\
\text { and/or brace with bilateral upper-extremity impairment; } \\
\text { usually not independent }\end{array}$ \\
\hline
\end{tabular}

* From Aghakhani et al., 2008. Modified from McCormick et al. Intramedullary ependymoma of the spinal cord. J Neurosurg 72:523-532, 1990. Published with permission.
224 patients with a histologically proven intraspinal NEC were treated at our institute. The presentations of the 13 patients included motor deficit (11 cases [84.6\%]), sensory disturbance (11 cases [84.6\%]), pain (6 cases [46.2\%]), and sphincter dysfunction (3 cases [23.1\%]). The mean duration of symptoms was 41.5 months (range 2-130 months). Five patients had intermittent symptoms, and 2 patients experienced sudden neurological deterioration in their clinical course. Nine patients had Grade II neurological status according to the modified McCormick classification, 3 had Grade III status, and 1 who had Grade Ib status (Table 2).

\section{Preoperative Imaging Diagnosis}

Cysts were located in the cervical cord (5 cases [38.5\%]), thoracic cord (3 cases [23.1\%]), cervicothoracic cord (1 case [7.7\%]), and the conus medullaris (4 cases [30.8\%]). Based on T1-weighted imaging (T1WI), the cyst exhibited hypointensity in 11 patients, isointensity in 1 patient, and mixed intensities in 1 patient. T2WI revealed that the cyst had hyperintensity in 11 patients and mixed intensities in 2 patients. Periphery enhancement of the cyst wall was observed on contrast-enhanced T1WI in 2 patients (Figs. $1-4)$. Ten lesions were misdiagnosed as ependymoma cyst (5 cases [38.5\%]), cystic dilation of the ventriculus terminalis (CDVT) (2 cases [15.4\%]), epidermoid cyst ( 1 case [7.7\%]), cystic meningioma (1 case [7.7\%]), or astrocytoma (1 case $[7.7 \%])$ respectively.

\section{Concurrent Malformations}

Plain radiography was performed in each case. Only 1 patient (Patient 4) underwent CT. Concurrent malformations occurred in 6 patients (46.2\%). The remaining 8 patients had normal findings on radiography. MRI revealed nonspecific abnormalities such as a tethered spinal cord in 1 case $(7.7 \%)$ and an enlarged spinal canal in another case $(7.7 \%)$. Plain radiography revealed scoliosis in 3 patients (23.1\%), fusion of rib in 1 patient $(7.7 \%)$, and ectocardia in 1 patient (7.7\%) (Fig. 5). Patient 4 had both an enlarged spinal canal and scoliosis. No other anomalies, such as hemivertebrae, spina bifida, or diastematomyelia, were detected. During the surgery, scoliosis usually hampers identification of the posterior midline. Concurrent scoliosis in our series was not treated surgically because of the following considerations: 1) regular postoperative examinations are necessary for intramedullary NECs, and spinal internal fixation devices may interfere with MRI, and 2) internal spinal instrumentation can result in barriers to potential reoperation because of cyst recurrence.

\section{Intraoperative Findings}

After opening the dura mater, a median myelotomy made in the posterior median sulcus revealed a cystic lesion. The cyst capsules varied from thin to thick walled, and the color was grayish white, creamy, or translucent. The cyst was gently punctured with a small needle, and the cyst fluid was aspirated slowly to avoid spillage into the subarachnoid space. The cyst fluid was viscous in 10 patients and CSF-like in 3 patients. Gross-total resection (GTR) was achieved in 8 cases (61.5\%), whereas subtotal 


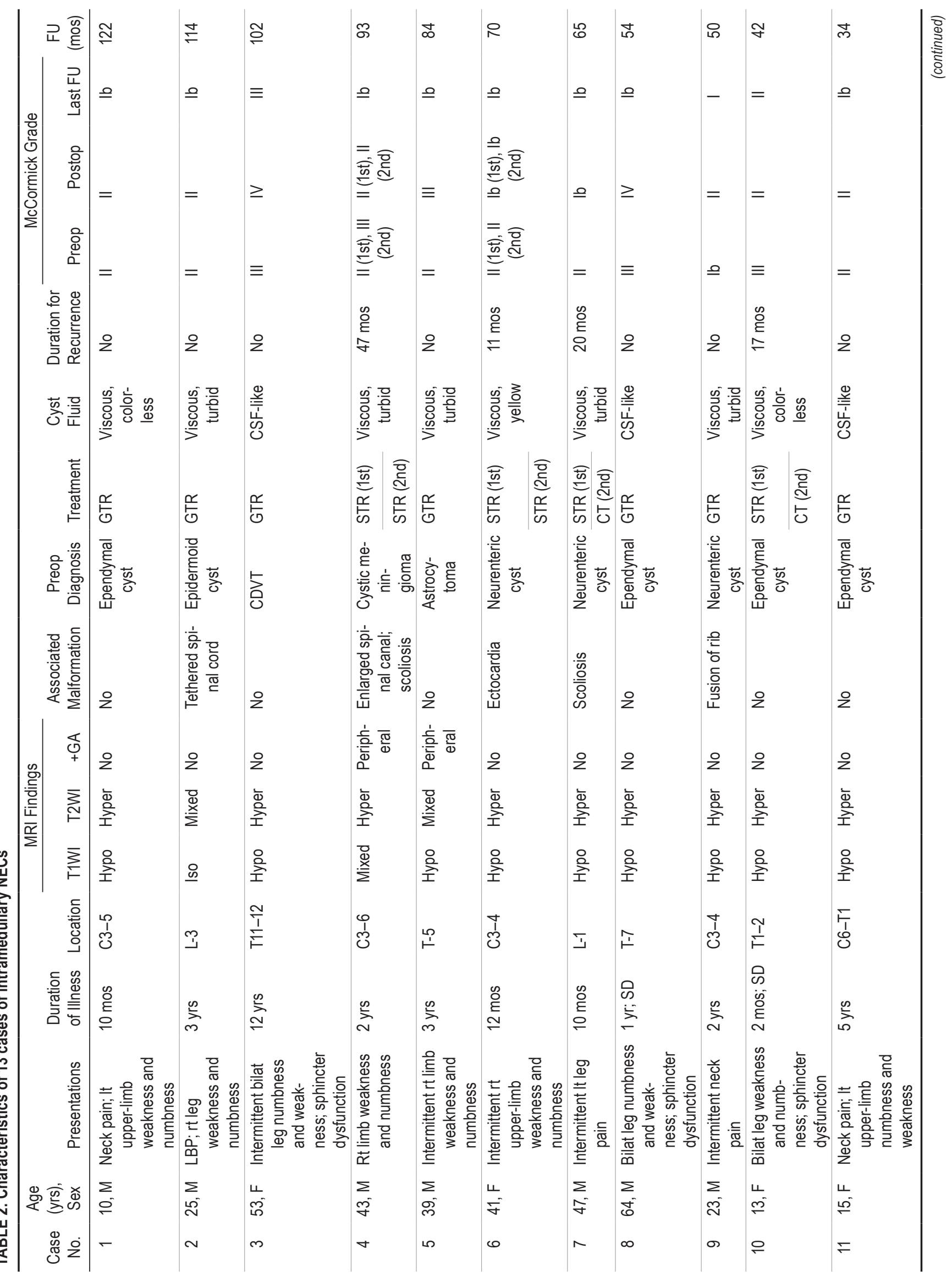




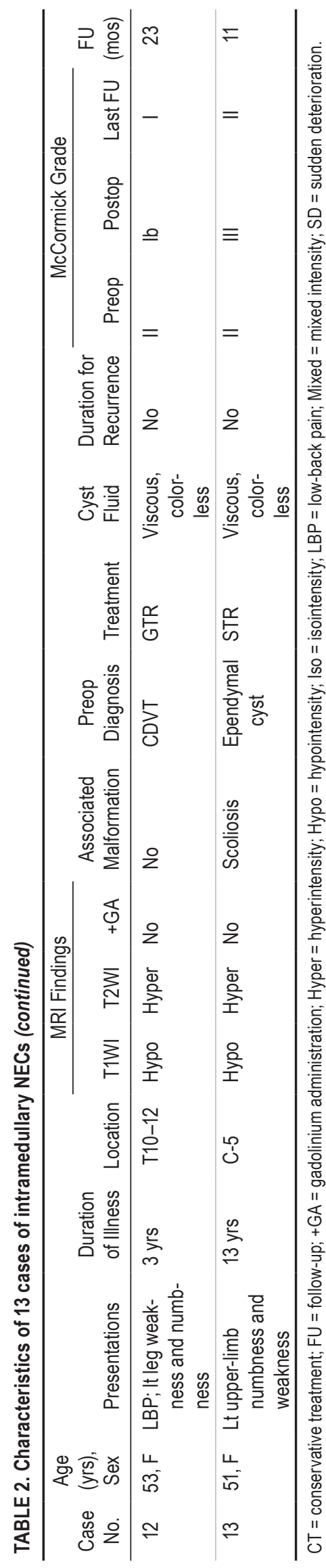

resection (STR) was achieved in 5 cases $(38.5 \%)$ with poor cyst-cord interfaces or dense adhesion to neural tissue. An illustrative example of a case is shown in Fig. 4.

\section{Pathological Examination}

Microscopically, the cyst wall was lined by pseudostratified, ciliated, columnar epithelium resting on a fibrocollagenous wall. An immunohistochemical examination revealed that the cells lining the cyst wall were positive for cytokeratin and epithelial membrane antigen (EMA) (Fig. 6). The epithelium was negative for glial fibrillary acidic protein (GFAP) and S-100 protein.

\section{Follow-Up}

The mean hospital length of stay was 17.3 days (range 13-25 days). Urinary tract infection occurred in 1 patient after surgery and was treated successfully by antibiotics. Another patient had a wound infection with healing disturbance, which resulted in CSF leakage and required lumbar drainage, wound repair, and antibiotic treatment. The postoperative periods ranged from 11 to 122 months (mean 66.5 months). In the immediate postoperative period, 5 patients who experienced worsening neurological function underwent MRI to determine if there was a postoperative hematoma. For these patients, MRI was not performed until 3 months after surgery. For the other 8 patients, MRI was performed at discharge. Patients for whom STR was performed underwent neurological examination and MRI semiannually thereafter. In patients for whom GTR was performed, neurological examinations and MRI were performed annually thereafter. At the last evaluation, status in 2 patients returned to modified McCormick Grade I. Status in 8 patients was Grade Ib; in 2 patients, Grade II; and in 1 patient, Grade III. Neurological function was improved in 11 patients $(84.6 \%)$ and remained stable in 2 patients (15.4\%). MRI showed no cyst recurrence in the 8 patients who underwent GTR in a mean follow-up period of 70 months. Cyst recurrence was observed in 4 patients after STR (Patients 4, 6,7, and 10). The median interval to recurrence after initial treatment was 23.6 months (range 6-261 months). In addition, no significant changes in spinal deformity were observed in any of the patients, not even for the youngest patient.

Patient 4 presented with progressive neck pain and weakness of the right upper limb 47 months after surgery. He underwent a reoperation after being diagnosed with cyst recurrence. An STR was achieved again. His neurological function improved, and no cyst recurrence was observed during another 46-month follow-up period. Patient 6 experienced rapid cyst recurrence after 11 months, and the recurrent cyst was subtotally resected. The patient's symptoms improved, and no cyst recurrence was observed during the second postoperative follow-up period. Patients 7 and 10 complained of limb numbness after surgery. However, there was no obvious increased volume of the recurrent cyst after a mean follow-up period of 35 months; moreover, these 2 patients remained clinically stable. Therefore, reoperation was not necessary, but the patients were still kept under close surveillance. 

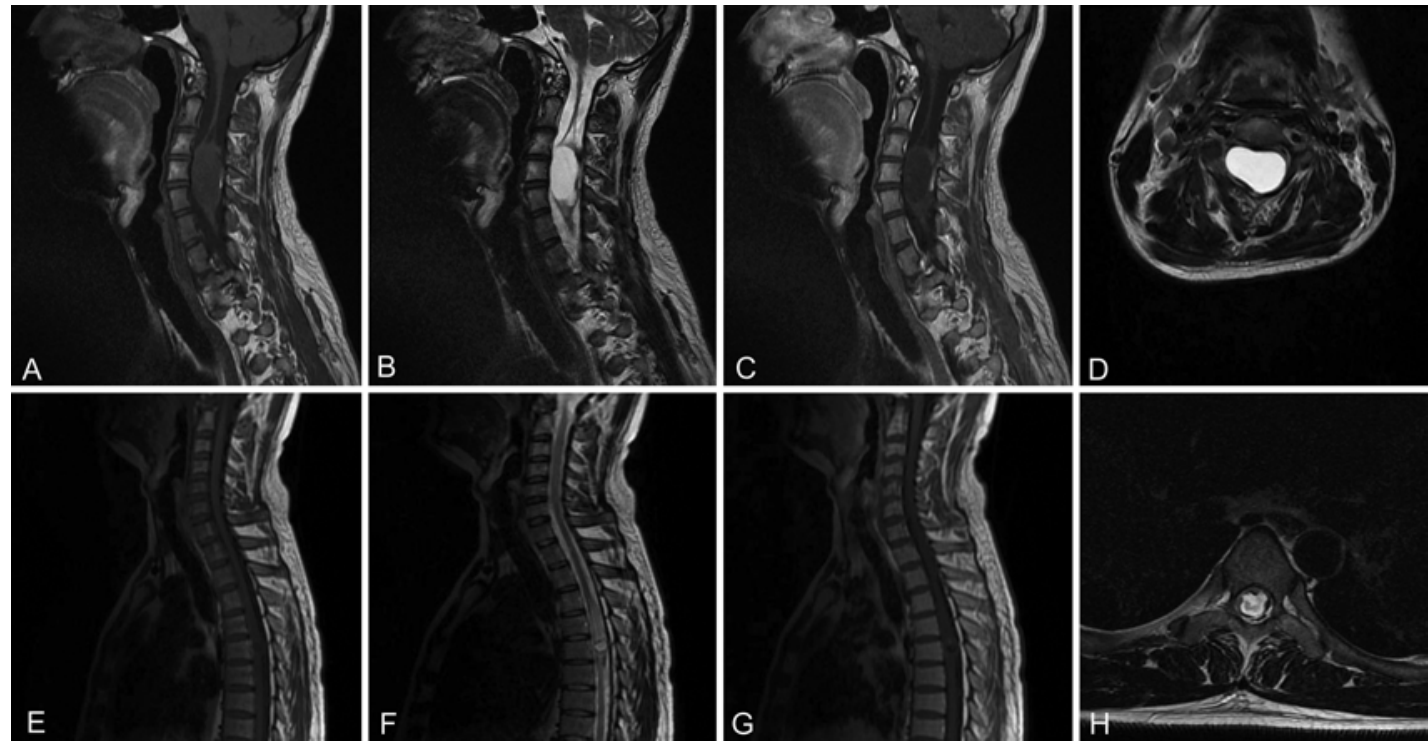

FIG. 1. Patient $4(A-D)$ and Patient $5(E-H)$. Patient 4. Preoperative MR images revealing an intramedullary lesion at $C 3-6$ and an enlarged spinal canal. A-D: The lesion shows mixed intensities on a sagittal T1WI scan (A) and hyperintensity on sagittal T2WI scan (B). C: Enhancement of the cyst wall is seen on a sagittal contrast-enhanced T1WI scan. D: Axial T2WI scan demonstrating the cyst filling almost the entire spinal cord. Patient 5. Preoperative MR images showing a well-defined cystic lesion at T-5 with peritumoral edema. The lesion shows hypointensity on a sagittal T1WI scan (E) and shows mixed intensities on a sagittal T2WI scan (F). G: Slight enhancement of the cyst wall is seen on a sagittal contrast-enhanced T1WI scan. H: Axial T2WI scan demonstrating that the cyst is located centrally in the spinal cord.

\section{Discussion}

\section{Review of the Literature}

Table 3 provides a summary of the 38 reported cases of intramedullary NECs. They usually manifest before the 4th decade of life (range 21 days to 68 years) and have a male predominance (male/female ratio 22:16). The le- sions are mostly located in the thoracic cord (11 cases), followed by the cervical cord (9 cases), cervicothoracic cord (8 cases), and the conus medullaris (10 cases). Progressive or intermittent motor deficits were the main symptoms, accompanied with or without pain or sensory deficits. $^{10,20-22,25,32-34,37-39}$ In 4 infants, they presented as a meningitis-like syndrome, probably resulting from rupture
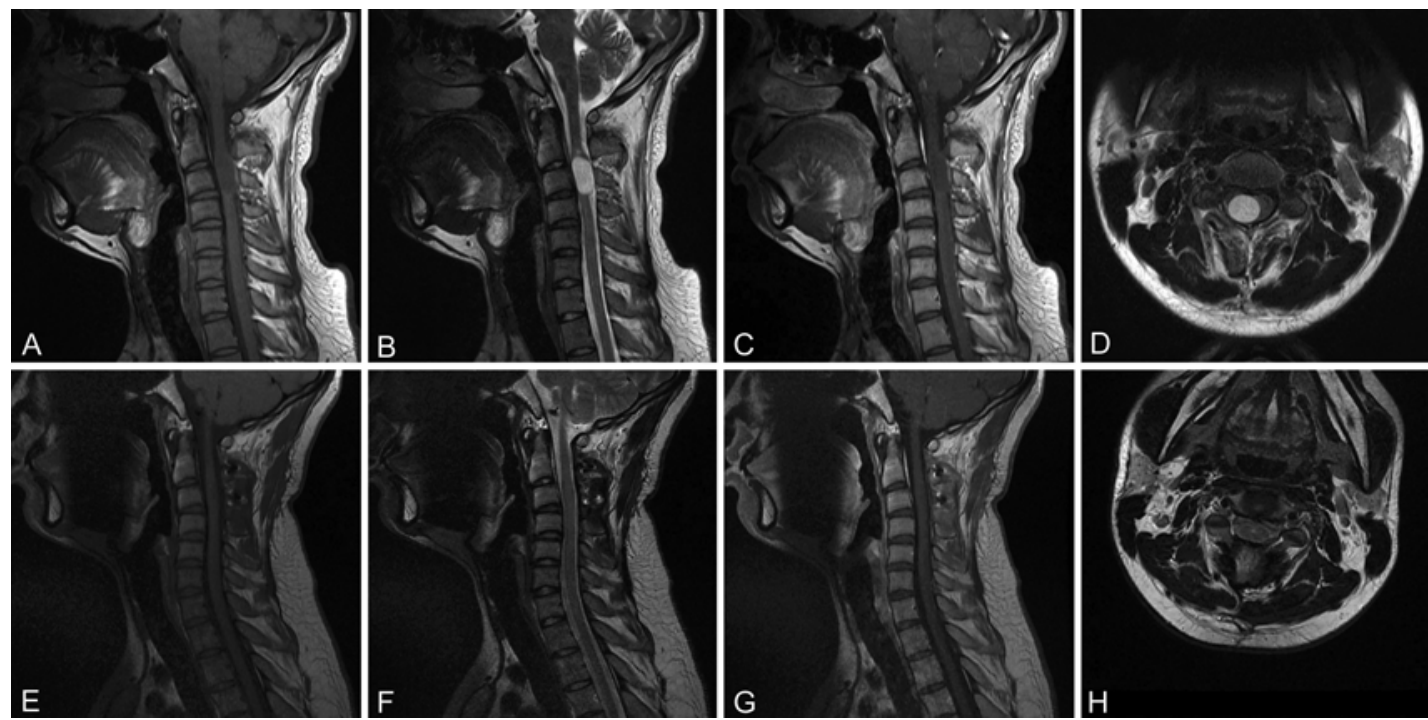

FIG. 2. Patient 9. A-D: Preoperative MRI scans showing a well-defined cystic lesion at C3-4. The lesion was slightly hyperintense to CSF on sagittal T1WI (A) and hyperintense on sagittal T2WI (B) scans. C: No enhancement of the cyst wall is seen on a sagittal contrast-enhanced T1WI scan. D: Axial T2WI scan demonstrating that the cyst is located centrally in the spinal cord. E-H: Three years after surgery, MRI scans showed no cyst recurrence, and the spinal cord has been decompressed (sagittal T1WI [E], sagittal T2WI [F], sagittal contrast-enhanced T1WI [G], and axial T2WI [H] scans). 
T. Yang et al.


FIG. 3. Patient 11. A-D: Preoperative MR images showing a well-defined cystic lesion at C6-T1. The lesion was hypointense on sagittal T1WI (A) and hyperintense on sagittal T2WI (B) scans. C: No enhancement of the cyst wall is seen on a sagittal contrastenhanced T1WI scan. D: Axial T2WI scan demonstrating that the cyst was filling almost the entire spinal cord. E-H: Two years after surgery, MR images showed no cyst recurrence and decompression of the spinal cord (sagittal T1WI [E], sagittal T2WI [F], sagittal contrast-enhanced T1WI [G], and axial contrast-enhanced T1WI [H] scans).

of the cyst into the subarachnoid space. ${ }^{8,14,19,26,40}$ Although commonly associated with other abnormalities, intraspinal NECs may be found without any abnormalities, and bone abnormalities were found in only 8 patients $(21.1 \%)$ with an intramedullary NEC., $318,19,21,24,37,40-42$ Surgical methods ranged from cyst puncture and aspiration ${ }^{25,39}$ to resection with cyst marsupialization or cyst-subarachnoid shunting. ${ }^{21,32,37}$ In the 38 reported cases, 33 patients underwent
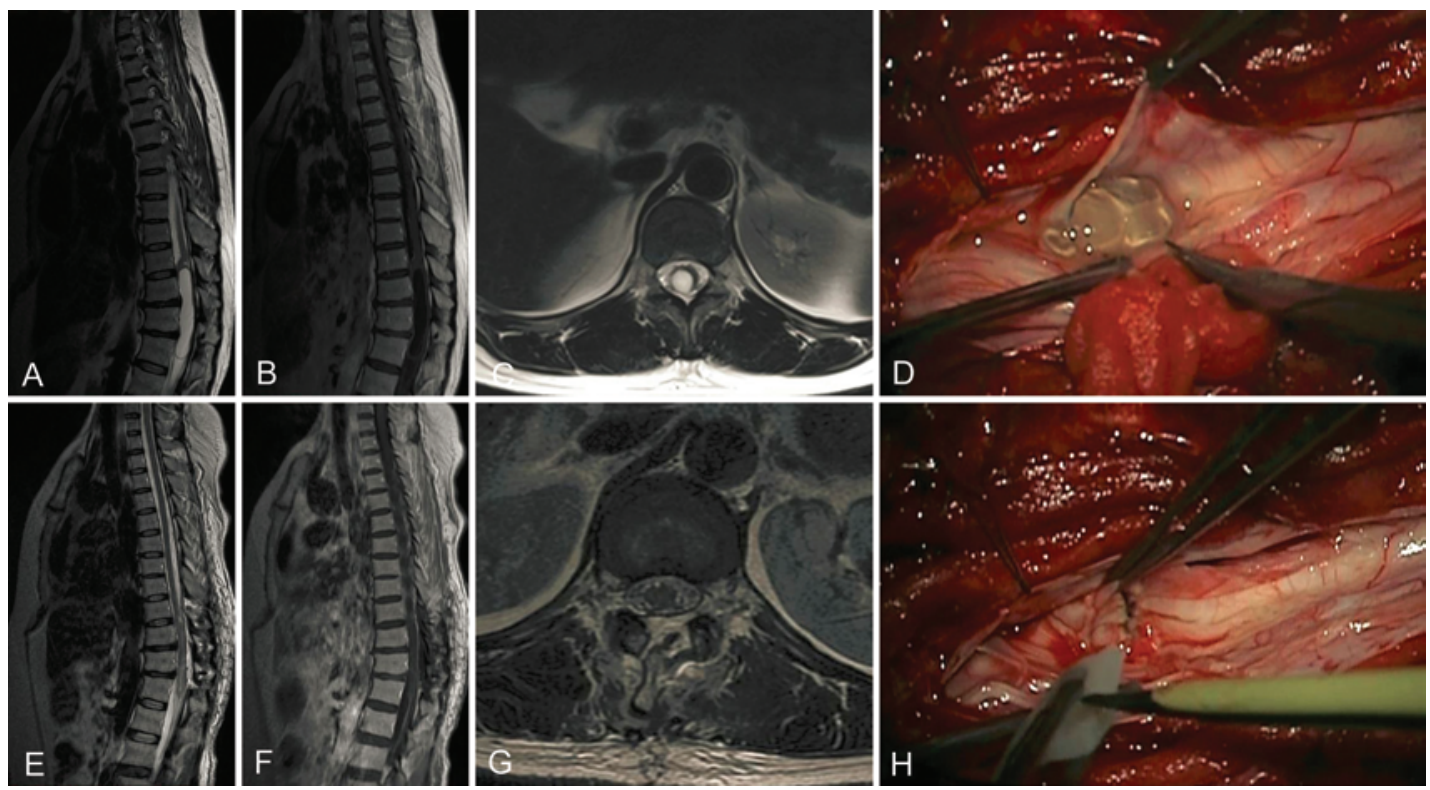

FIG. 4. Patient 12. A-D: Preoperative MRI scans showing a well-defined cystic lesion in the conus medullaris. A: The lesion was hyperintense on a sagittal T2WI scan. B: No enhancement of the cyst wall is seen on a contrast-enhanced T1WI scan. C: Axial T2WI scan demonstrating that the cyst is located centrally in the spinal cord. D: After T10-12 laminotomy and midline myelotomy, a translucent intramedullary cyst is seen with a well-demarcated dissection plane. E-H: Postoperative MR images (sagittal T1WI $[E]$, sagittal T2WI [F], and axial T2WI [G] scans) and intraoperative photograph (H) revealed total excision of the cyst. Figure is available in color online only. 



FIG. 5. Plain radiographs showing C-shaped cervicothoracic scoliosis with a single curve (Patient 4 [A]), ectocardia (Patient 6 $[B])$, and fusion of the right fourth to sixth ribs (Patient $9[\mathrm{C}]$ ).

surgical resection, and GTR was achieved in 17 cases. Seven patients experienced cyst recurrence during the follow-up period.

\section{Epidemiology and Clinical Futures}

NECs are rare congenital lesions of endodermal origin and account for approximately $0.7 \%-1.3 \%$ of primary spinal cord "tumors." 11 Most intraspinal NECs are located in the IDEM space and are often situated ventral to the spinal cord..$^{45}$ Intramedullary NECs are very rare and account for $<5 \%$ of intraspinal NECs. ${ }^{22}$ Our series adds 13 patients, which is a substantial addition to the existing literature. In our study, intramedullary NECs comprised $5.8 \%$ of all intraspinal NECs treated at our institute and showed no sex predilection. The incidence of cervical cord (38.5\%) and conus medullaris $(30.8 \%)$ locations was close to that in the literature; NECs at these locations may be caused by late closure of the neural tube at the extremes of the spinal cord. .11,25,26 $^{2}$

The presentations of intramedullary NECs are variable and depend on both lesion site and size. ${ }^{24}$ Compared with IDEM NECs, intramedullary NECs always present with myelopathic symptoms. The most common symptom is motor deficit, followed by sensory disturbance, pain, and sphincter dysfunction. ${ }^{2}$ In our series, the duration between symptom onset and presentation was very long (mean 41.5 months), which probably reflected the slow growth pattern of the cyst. However, sudden neurological deterioration occurred in 2 cases. de Oliveira ${ }^{10}$ speculated that this deterioration was caused by mechanical compression of a sudden increase in the cyst volume as the result of an accumulation of cyst fluid. However, this hypothesis needs to be confirmed.

In our study, 5 patients had intermittent symptoms that were characterized by exacerbation and remission. This characteristic has been explained by periodic rupture of the cyst contents into the subarachnoid space..$^{20,30,33}$ Nevertheless, no patient in our series presented with a meningitis-like syndrome. Riviérez et al. ${ }^{32}$ postulated that a fluctuation in the rates of active mucin secretion and resorption by the cyst wall may also be related to intermittent symptoms. Although the exact cause is not clear, the intermittent symptoms can still give us a clue to the diagnosis of NECs. ${ }^{17}$

\section{Pathogenesis}

The occurrence of NECs is exceedingly rare, and the precise pathogenesis is still unknown. The various theories are as follows: 1) splitting of the notochord as the primary event, ${ }^{6}$ 2) ectopic abnormal accessory neuroenteric canals cephalad to the coccygeal tip, ${ }^{5}$ and 3) focal adhesions between the endoderm and ectoderm within the primitive streak. ${ }^{7}$ The most widely accepted mechanism is that proposed by Bentley and Smith, ${ }^{6}$ who suggested that the primary event is a split notochord with an associated deficiency in the neural plate, which allows an endodermal diverticulum to herniate through the defect and come into contact with the ectoderm. In addition, the intramedullary NEC is regarded as a cyst located in the spinal cord, with the tissue most likely derived from the spinal cord itself. ${ }^{26}$ This theory is attractive, because it provides an easily understandable mechanism. However, it cannot explain the formation of NECs in their entirety, such as formation of intracranial lesions. ${ }^{40,41}$ Thus, various pathogenic mechanisms may cause these lesions.


FIG. 6. A and B: Photomicrographs of the surgical specimens illustrating a cyst lined by pseudostratified, ciliated, columnar epithelium resting on a fibrocollagenous wall. $H \& E$, original magnification $\times 100(A)$ and $\times 200$ (B). C and D: In the immunohistochemical analysis, the cells lining the cyst wall tested positive for cytokeratin (C) and EMA (D). Original magnification $\times 200$. Figure is available in color online only. 


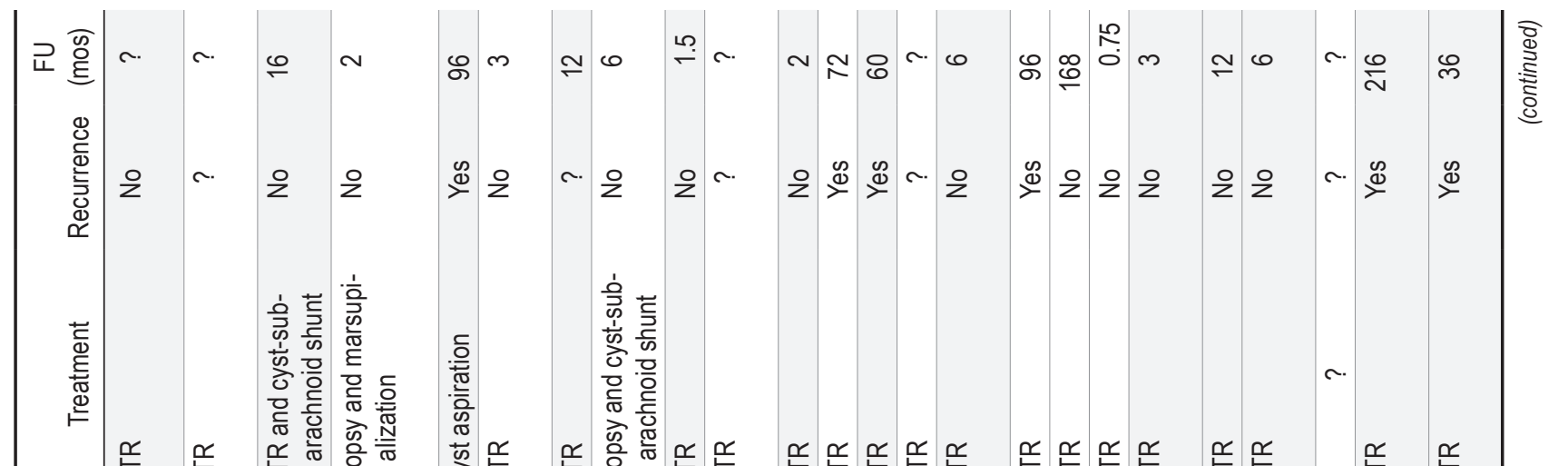

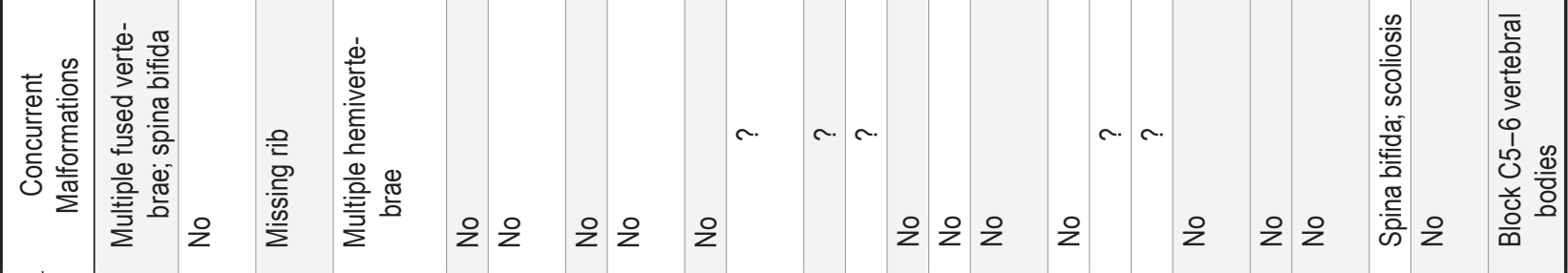

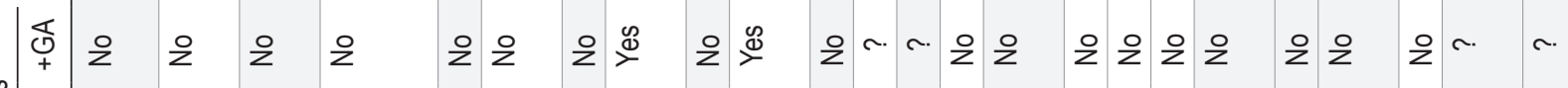

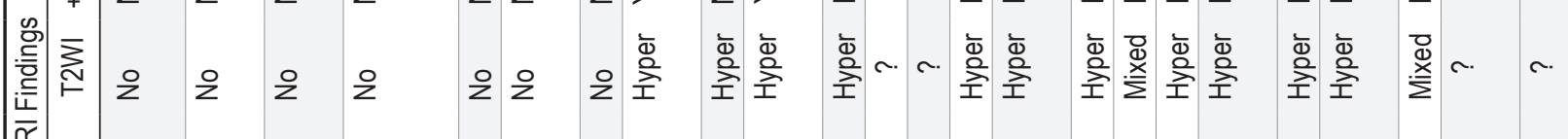

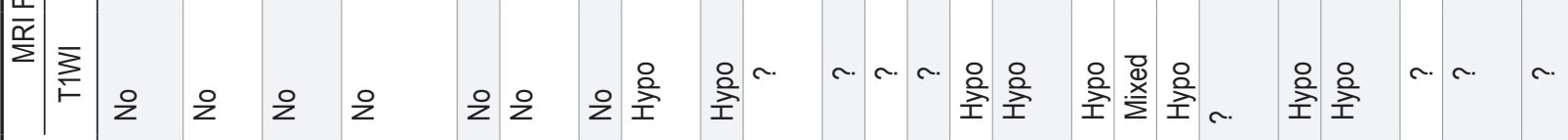

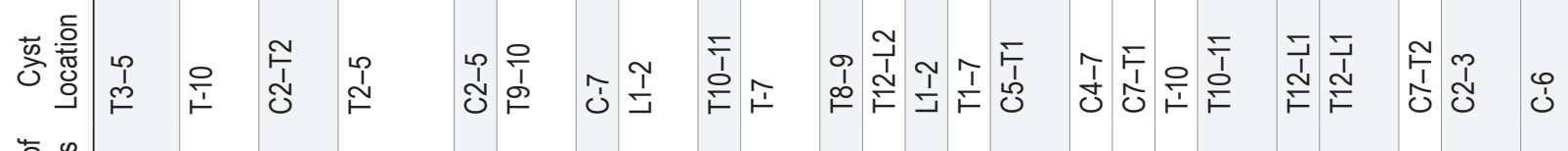

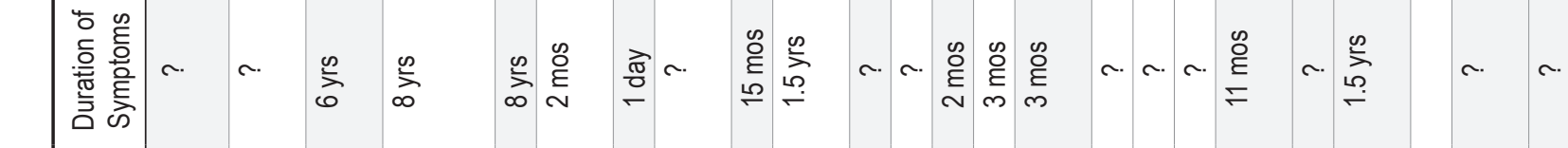

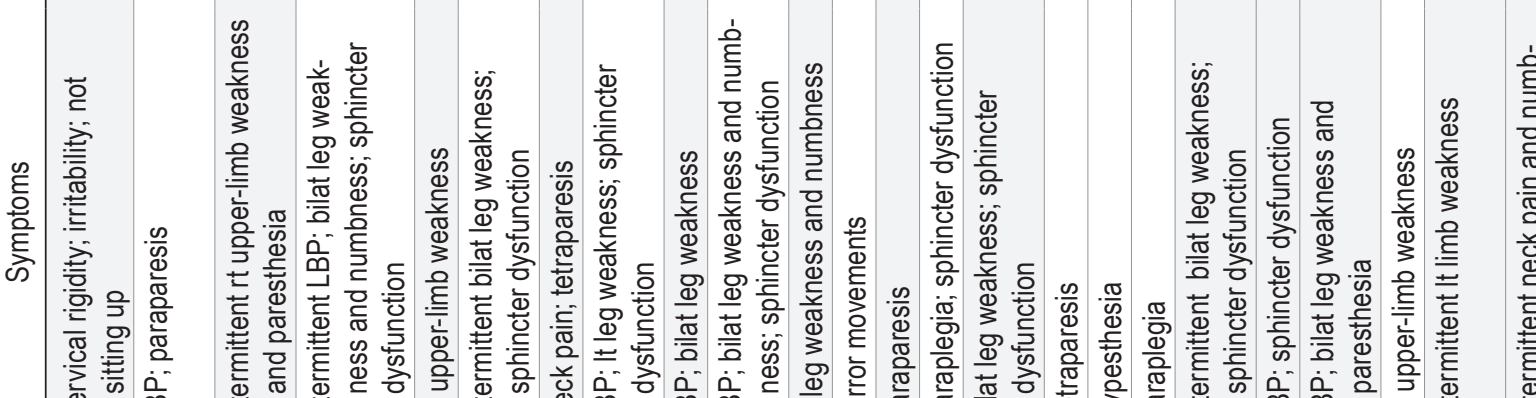

妥

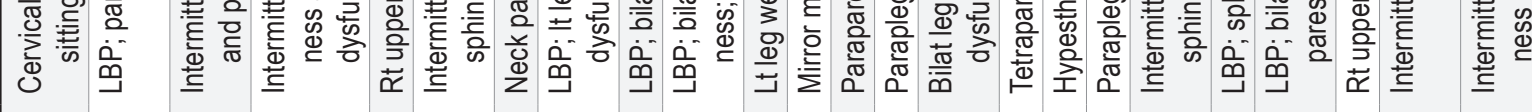

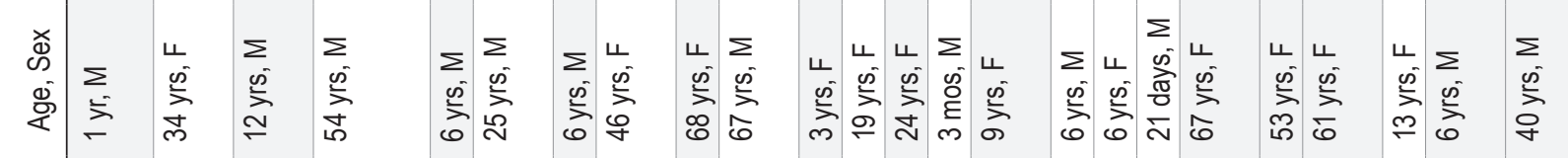



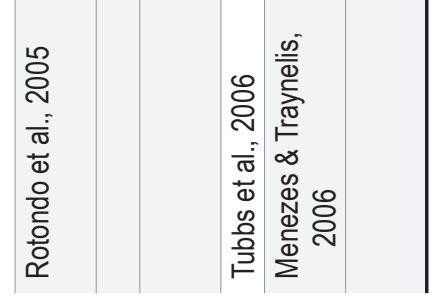









\section{Diagnosis and Differentiation}

Because MRI provides the exact location and extent of the cyst, and the degree of spinal cord compression, it has become the most important tool for diagnosing intraspinal NECs. ${ }^{10,24}$ Additional CT scanning is recommended to help rule out any concurrent bone abnormalities ${ }^{22,27}$ however, MRI can also provide a complete noninvasive assessment of bony abnormalities, especially with continued increases in the precision of associated computer software..$^{20,26,38} \mathrm{In}$ our series, CT was performed in only 1 case. Each patient underwent plain radiography and MRI, and all of the bone abnormalities were diagnosed preoperatively. Thus, we advocate $\mathrm{CT}$ as just an alternative method for diagnosing intramedullary NECs with doubtful abnormalities seen with MRI or plain radiography.

On MRI, intramedullary NECs are generally well marginated, regularly shaped, isointense or slightly hyperintense to CSF on T1WI, isointense or hyperintense to CSF on T2WI, and not enhanced on contrast T1WI. These variable signal characteristics are thought to correlate with the protein-rich fluid, which is usually described during surgery as milky or viscous. ${ }^{28,33}$ Ziu et al. ${ }^{45}$ and Rotondo et al. ${ }^{33}$ stated that confident MRI diagnosis of an NEC is based on the presence of an intraspinal cyst that is associated with concurrent malformations such as bone anomalies. In our 13 cases, bone anomalies were identified in $30.8 \%$ of the patients, which was a slightly higher rate than that in the literature on intramedullary NECs. ${ }^{3,18,19,21,24,37,40,41}$ In contrast, bone anomalies were more common in extramedullary NECs..$^{12}$ Thus, the diagnosis of an isolated intramedullary NEC without concurrent malformations becomes even more challenging.

Generally, the lack of enhancement of the cyst wall can help differentiate NECs from cystic neoplasms. ${ }^{22}$ In 2 cases in our series, enhancing cyst walls were misdiagnosed as cystic meningioma or astrocytoma. Similarly, Muzumdar et al. ${ }^{26}$ described an NEC with an abscess or granulomalike presentation associated with enhancement of the cyst wall on MRI. It may have been caused by a chronic inflammatory reaction to the cyst fluid after spontaneous periodic minute ruptures in the cyst wall membrane ${ }^{26}$ Signal intensity of intramedullary ependymal cysts, syringomyelia, and CDVT is always isointense to CSF. It is difficult to radiologically distinguish these conditions from NEC, especially when NEC fluid has the same intensity to CSF. Therefore, an accurate diagnosis still depends on pathology. H \& E staining is not sufficient to differentiate ependymal cysts and NECs because of similar microscopic morphologies. ${ }^{15}$ Thus, immunohistochemistry is essential. Ependymal cysts are positive for GFAP and S-100 protein, ${ }^{15}$ both of which are glial markers expressed by normal ependymal epithelium. However, NECs are generally positive for EMA and cytokeratin and negative for GFAP and S-100 protein. 22,32

\section{Treatment}

Because chronic cord compression is the main pathogenic mechanism of intramedullary NECs, the first choice for treatment is surgery with the goal of neural decompression and prevention of cyst refilling. ${ }^{25}$ For most IDEM NECs, GTR can be achieved easily because of a clear plane of dissection between the cyst wall and the spinal cord. The GTR rates for IDEM NECs in the literature range from $71 \%$ to $75 \%{ }^{8,10,12}$ However, GTR is not feasible for intramedullary NECs. In 8 cases in the present study, the cyst wall showed no adhesion to the spinal cord, and GTR was achieved by using microsurgical techniques. In the other 5 cases, GTR was impossible because of poor cyst-spinal cord interfaces or severe adhesion to the spinal cord. For these NECs, overaggressive resection is dangerous and should be avoided.

Although Takahashi et al. ${ }^{39}$ recommended MRI-guided percutaneous aspiration as the treatment of choice, simple aspiration is less desirable, because it cannot yield a pathological diagnosis and results in a high recurrence

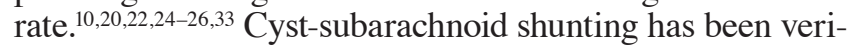
fied to be effective for ependymal cysts; ${ }^{43}$ however, whether it is suitable for intramedullary NECs remains controversial. The method was thought to be simple and can prevent cyst recurrence, ${ }^{30}$ but more authors have rejected it because the spillage of caustic cyst contents into the subarachnoid space might cause inflammation of the neural elements. ${ }^{22,33}$ In most intramedullary NECs in our study, the cyst fluid had a viscous appearance, obviously different from CSF-like fluid in ependymal cysts. In consideration of postoperative aseptic meningitis, we reject the use of cyst-subarachnoid shunting. We performed maximally safe removal and avoided spillage of the cyst fluid. Intraoperative neuromonitoring significantly decreases the risk of neurological deficits. ${ }^{22} \mathrm{Had}$ the intraoperative warning not been provided by motor evoked potential changes, we would have continued the resection. In our study, $84.6 \%$ of the patients experienced an improvement in their modified McCormick grade, and $15.4 \%$ of the patients maintained their pretreatment status. Although transient postoperative neurological deterioration was observed in 5 patients, at the 3rd month, neurological examination revealed that 3 patients had improved with rehabilitation therapy. However, the symptoms persisted in 2 patients $(1$ after GTR and 1 after STR ) for $>10$ years. Long-lasting compression of the cyst or cyst rupture within the spinal cord could cause irreversible neurological deficits. ${ }^{33}$ For symptomatic intramedullary NECs, timely surgery is very important.

Because of the continued secretion of residual epithelium or accumulation of CSF in the residual cavity of the cyst, NECs may recur, and long-term radiological followup is needed. ${ }^{12,25}$ The recurrence rates of IDEM NECs range from $0 \%$ to $37 \%{ }^{8,9}$ We reviewed the literature and found the recurrence rate of intramedullary NECs to be $23.3 \%$. We believe that the real value was higher than that, because nearly half of the reported patients had no or relatively short-term follow-up ( $<1$ year). In our series, the recurrence rate was $30.8 \%$. No recurrence was observed in the GTR group, and 4 cyst recurrences were observed in the STR group at after a mean follow-up period of 23.6 months.

Currently, there is no evidence that radiotherapy reduces the risk of NEC recurrence. Because of the inflammatory reaction caused by epithelial secretion, the resection of a recurrent cyst is technically difficult. ${ }^{26}$ In our series, 2 recurrent cysts were subtotally resected, and the patients 
recovered well. Thus, timely reoperation with a goal of STR is recommended when a residual cyst shows obvious regrowth and results in neurological deficits. ${ }^{36}$

\section{Conclusions}

Intramedullary NECs should be considered in the differential diagnosis of a middle-aged patient with intermittent neurological symptoms and concurrent malformations. Early surgery is advocated to prevent permanent neurological deficits. When GTR of the lesion cannot be achieved, maximally safe removal under the protection of intraoperative neuromonitoring is advised. Because of the high risk of cyst recurrence, routine follow-up MRI is needed. If a residual cyst shows obvious regrowth and results in neurological deficits, timely reoperation (STR) should be performed.

\section{Acknowledgments}

We thank all of the patients who trusted us and all the physicians and staff who helped with this study.

\section{References}

1. Aghakhani N, David P, Parker F, Lacroix C, Benoudiba F, Tadie M: Intramedullary spinal ependymomas: analysis of a consecutive series of 82 adult cases with particular attention to patients with no preoperative neurological deficit. Neurosurgery 62:1279-1286, 2008

2. Agrawal D, Suri A, Mahapatra AK, Sharma MC: Intramedullary neurenteric cyst presenting as infantile paraplegia: a case and review. Pediatr Neurosurg 37:93-96, 2002

3. Aydin AL, Sasani M, Ucar B, Afsharian R, Ozer AF: Prenatal diagnosis of a large, cervical, intraspinal, neurenteric cyst and postnatal outcome. J Pediatr Surg 44:1835-1838, 2009

4. Balasubramaniam S, Tyagi DK, Sawant HV: Intramedullary enterogenous cyst of the conus medullaris presenting as lower limb pain. J Craniovertebr Junction Spine 2:46-48, 2011

5. Beardmore HE, Wiglesworth FW: Vertebral anomalies and alimentary duplications; clinical and embryological aspects. Pediatr Clin North Am 5:457-474, 1958

6. Bentley JF, Smith JR: Developmental posterior enteric remnants and spinal malformations: the split notochord syndrome. Arch Dis Child 35:76-86, 1960

7. Bremer JL: Dorsal intestinal fistula; accessory neurenteric canal; diastematomyelia. AMA Arch Pathol 54:132-138, 1952

8. Cai C, Shen C, Yang W, Zhang Q, Hu X: Intraspinal neurenteric cysts in children. Can J Neurol Sci 35:609-615, 2008

9. Chavda SV, Davies AM, Cassar-Pullicino VN: Enterogenous cysts of the central nervous system: a report of eight cases. Clin Radiol 36:245-251, 1985

10. de Oliveira RS, Cinalli G, Roujeau T, Sainte-Rose C, PierreKahn A, Zerah M: Neurenteric cysts in children: 16 consecutive cases and review of the literature. J Neurosurg 103 (6 Suppl):512-523, 2005

11. Fortuna A, Mercuri S: Intradural spinal cysts. Acta Neurochir (Wien) 68:289-314, 1983

12. Garg N, Sampath S, Yasha TC, Chandramouli BA, Devi BI, Kovoor JM: Is total excision of spinal neurenteric cysts possible? Br J Neurosurg 22:241-251, 2008

13. Jain AK, Sethi S, Arora A, Tuli SM, Singh RP: Enterogenous intramedullary cyst. Indian Pediatr 31:224-228, 1994
14. Jhawar SS, Mahore A, Goel A: Intramedullary spinal neurenteric cyst with fluid-fluid level. J Neurosurg Pediatr 9:542-545, 2012

15. Kato M, Nakamura H, Suzuki E, Terai H, Wakasa K, Wakasa $\mathrm{T}$, et al: Ependymal cyst in the lumbar spine associated with cauda equina compression. J Clin Neurosci 15:827-830, 2008

16. Khandelwal N, Malik N, Khosla VK, Radotra B: Intramedullary enterogenous cyst. Australas Radiol 37:272273, 1993

17. Kim CY, Wang KC, Choe G, Kim HJ, Jung HW, Kim IO, et al: Neurenteric cyst: its various presentations. Childs Nerv Syst 15:333-341, 1999

18. Klekamp J: Tethered cord syndrome in adults. J Neurosurg Spine 15:258-270, 2011

19. Knight G, Griffiths T, Williams I: Gastrocystoma of the spinal cord. Br J Surg 42:635-638, 1955

20. Kumar R, Nayak SR: Unusual neuroenteric cysts: diagnosis and management. Pediatr Neurosurg 37:321-330, 2002

21. Kwok DM, Jeffreys RV: Intramedullary enterogenous cyst of the spinal cord. Case report. J Neurosurg 56:270-274, 1982

22. Lippman CR, Arginteanu M, Purohit D, Naidich TP, Camins MB: Intramedullary neurenteric cysts of the spine. Case report and review of the literature. J Neurosurg 94 (2 Suppl):305-309, 2001

23. McCormick PC, Torres R, Post KD, Stein BM: Intramedullary ependymoma of the spinal cord. J Neurosurg 72:523-532, 1990

24. Menezes AH, Traynelis VC: Spinal neurenteric cysts in the magnetic resonance imaging era. Neurosurgery 58:97-105, 2006

25. Mizuno J, Fiandaca MS, Nishio S, O'Brien MS: Recurrent intramedullary enterogenous cyst of the cervical spinal cord. Childs Nerv Syst 4:47-49, 1988

26. Muzumdar D, Bhatt Y, Sheth J: Intramedullary cervical neurenteric cyst mimicking an abscess. Pediatr Neurosurg 44:55-61, 2008

27. Nagi S, Ghorbel D, Drissi C, Maatallah Y, Hammami N, Hamouda M: Intramedullary neurenteric cyst without concurrent malformation. Australas Radiol 51:B14-B17, 2007

28. Paolini S, Ciappetta P, Domenicucci M, Guiducci A: Intramedullary neurenteric cyst with a false mural nodule: case report. Neurosurgery 52:243-246, 2003

29. Rauzzino MJ, Tubbs RS, Alexander E III, Grabb PA, Oakes WJ: Spinal neurenteric cysts and their relation to more common aspects of occult spinal dysraphism. Neurosurg Focus 10(1):E2, 2001

30. Reinders JW, Wesseling P, Hilkens PH: Intramedullary enterogenous cyst presenting with spastic paraparesis during two consecutive pregnancies: a case report. J Neurol Neurosurg Psychiatry 71:528-530, 2001

31. Rewcastle NB, Francoeur J: Teratomatous cysts of the spinal canal: with "sex chromatin" studies. Arch Neurol 11:91-99, 1964

32. Riviérez M, Buisson G, Kujas M, Ridarch A, Mignon E, Jouannelle A, et al: Intramedullary neurenteric cyst without any associated malformation. One case evaluated by RMI and electron microscopic study. Acta Neurochir (Wien) 139:887-890, 1997

33. Rotondo M, D’Avanzo R, Natale M, Pasqualetto L, Bocchetti A, Agozzino L, et al: Intramedullary neurenteric cysts of the spine. Report of three cases. J Neurosurg Spine 2:372-376, 2005

34. Sadeghi-Hariri B, Khalatbari MR, Hassani H, Taheri B, Abbassioun K: Intramedullary neurenteric cyst of the conus medullaris without associated spinal malformation: a case report and review of the literature. Turk Neurosurg 22:478482,2012

35. Sharma RR, Ravi RR, Gurusinghe NT, Coutinho C, 
Mahapatra AK, Sousa J, et al: Cranio-spinal enterogenous cysts: clinico-radiological analysis in a series of ten cases. $\mathbf{J}$ Clin Neurosci 8:133-139, 2001

36. Shetty SR, Panigrahi M, Rao S: Neurenteric cyst at the craniovertebral junction: A report of two cases. Asian J Neurosurg 8:188-191, 2013

37. Silvernail WI Jr, Brown RB: Intramedullary enterogenous cyst. Case report. J Neurosurg 36:235-238, 1972

38. Singhal BS, Parekh HN, Ursekar M, Deopujari CE, Manghani DK: Intramedullary neurenteric cyst in mid thoracic spine in an adult: a case report. Neurol India 49:302304, 2001

39. Takahashi S, Morikawa S, Saruhashi Y, Matsusue Y, Kawakami M: Percutaneous transthoracic fenestration of an intramedullary neurenteric cyst in the thoracic spine with intraoperative magnetic resonance image navigation and thoracoscopy. J Neurosurg Spine 9:488-492, 2008

40. Theret E, Litre CF, Lefebvre F, Eap C, Duntze J, Scherpereel $\mathrm{B}$, et al: Huge intramedullar neurenteric cyst with intrathoracic development in a 1 month-old boy: excision though the anterior approach. A case report and review of the literature. Acta Neurochir (Wien) 152:481-483, 2010

41. Tubbs RS, Salter EG, Oakes WJ: Neurenteric cyst: case report and a review of the potential dysembryology. Clin Anat 19:669-672, 2006

42. Vachhani JA, Fassett DR: Intramedullary neurenteric cyst associated with a tethered spinal cord: Case report and literature review. Surg Neurol Int 3:80, 2012
43. Yang T, Wu L, Deng X, Yang C, Fang J, Zhao L, et al: Clinical characteristics and surgical outcomes of spinal intramedullary ependymal cysts. Acta Neurochir (Wien) 156:269-275, 2014

44. Yilmaz C, Gulsen S, Sonmez E, Ozger O, Unlukaplan M, Caner H: Intramedullary bronchogenic cyst of the conus medullaris. J Neurosurg Spine 11:477-479, 2009

45. Ziu M, Vibhute P, Vecil GG, Henry J: Isolated spinal neurenteric cyst presenting as intramedullary calcified cystic mass on imaging studies: case report and review of literature. Neuroradiology 52:119-123, 2010

\section{Author Contributions}

Conception and design: T Yang, Wu. Acquisition of data: Xu, T Yang, Fang. Analysis and interpretation of data: T Yang, C Yang. Drafting the article: $\mathrm{T}$ Yang. Critically revising the article: all authors. Reviewed submitted version of manuscript: all authors. Approved the final version of the manuscript on behalf of all authors: Xu. Statistical analysis: T Yang, Deng. Administrative/ technical/material support: Xu. Study supervision: Xu.

\section{Correspondence}

Yulun Xu, Department of Neurosurgery, Beijing Tiantan Hospital, Capital Medical University, No. 6 Tiantan Xili, Dongcheng District, Beijing 100050, China. email: xuhuxi@sina. com. 